\title{
Calf- and herd-level factors associated with dairy calf reactivity
}

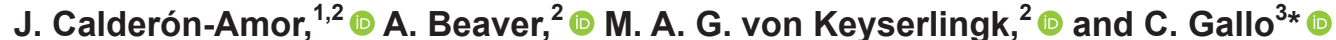 \\ ${ }^{1}$ Escuela de Graduados, Facultad de Ciencias Veterinarias, Universidad Austral de Chile, Valdivia 5090000, Chile \\ ${ }^{2}$ Animal Welfare Program, Faculty of Land and Food Systems, University of British Columbia, 2357 Mall, Vancouver, BC, Canada, V6T 124 \\ ${ }^{3}$ Instituto de Ciencia Animal, Facultad de Ciencias Veterinarias, OIE Collaborating Centre for Animal Welfare \\ and Livestock Production Systems—Chile, Universidad Austral de Chile, Valdivia 5090000, Chile
}

\section{ABSTRACT}

A positive relationship between handlers and animals in farm systems is essential because the human-animal relationship has implications for welfare and productivity. For this reason, on-farm animal welfare assessment protocols often include the behavioral response of animals to humans to measure the quality of the human-animal relationship. The existing literature has described this relationship as being multifactorial in nature. In the current study, we aimed to investigate the potential influence of farm management and infrastructure characteristics, calf manager traits, and intrinsic features of dairy calves on the human-animal relationship. To this end, an escape test was conducted with 698 calves on 30 dairy farms in Chile. This test measured the calf's response to the active approach of an unfamiliar human (and was scored from 0 [fearful] to 4 [friendly]). The explanatory variables used to predict calves' response in the escape test were grouped according to the following categories: (1) farm management and infrastructure (e.g., calf-dam separation age, space allowance); (2) calf manager (e.g., attitudes, behavior, and background); and (3) calf (e.g., breed, sex, age). We concluded that calf managers with additional jobs on the farm, no training, low job satisfaction, a greater proportion of negative contacts, and more negative attitudes were predictive of fearfulness in the escape test. Holstein breed (compared with Holstein and Jersey crossbreeds) was associated with greater odds of fearful calves. Our study confirms the association between animals' fear and handlers' features, which can potentially be used to select employees on a farm. Understanding the factors that influence fear responses in calves may highlight ways to improve the relationship between animals and humans.

Key words: human-animal relationship, animal welfare, dairy calf

Received April 29, 2019.

Accepted December 28, 2019.

*Corresponding author: cgallo@uach.cl

\section{INTRODUCTION}

Ensuring the welfare of dairy calves is challenging due to the many interdependent factors that can influence welfare status. The human-animal relationship (HAR) is a significant contributor to animal welfare at behavioral, physiological, and productive levels (Waiblinger et al., 2006; Hemsworth and Coleman, 2011); thus, a greater understanding of HAR represents a potential focal point for improving animal welfare. According to Hemsworth and Coleman (2011), the quality of HAR is built upon a repertoire of relevant interactions and is determined by the context in which they occur. For farm animals, this relationship is governed by the constant contact with humans who care for them, and it can be classified as positive, negative, or neutral for the animal (Hemsworth and Coleman, 2011).

The quality of HAR can be assessed by observing the interactions between the farmer or other humans and the animals under their care (Hemsworth and Coleman, 2011). Waiblinger et al. (2006) described 3 methods to assess the reactivity of animals to humans: responses to handling, reactivity toward a stationary human, and reactivity toward a person in movement. The Calf Escape Test with an Unfamiliar Person (escape test) conducted in the home environment falls into the final category. The escape test is easily performed on commercial farms, and the influence of potential confounding factors is reduced when the test is carried out in the animals' familiar environment. Results from escape tests performed with a familiar and an unfamiliar person are highly correlated, and the test also has high interobserver and high test-retest reliability (Bokkers et al., 2009). One potential disadvantage is the potentially subjective interpretation; for example, animals that do not move might be motivated by fear or by indifference (Waiblinger et al., 2006).

The behavioral responses of animals to humans are varied and depend on dynamics of human-animal interactions, with fear being the most commonly evaluated (Lensink et al., 2001; Waiblinger et al., 2006). The first and main reaction of fearful animals is escape-avoid- 
ance behavior that can lead to acute and chronic stress, immunosuppression, and health problems (Breuer et al., 2003; Hemsworth, 2003). In the study by Munksgaard et al. (1997), lactating cows were assigned to 2 treatments: aversive (strike with the hand on the cow's head) and gentle handling (offer food, gently stroking, and friendly voice). After treatment, cows were capable of distinguishing among handlers, keeping greater distances from the aversive handler; in addition, the cows defecated and urinated more during the aversive treatment. Negative interactions between the handler and lactating cows have previously been associated with fewer cows approaching an experimenter and with increased milk cortisol concentrations (Hemsworth et al., 2000). A positive correlation has also been observed between approaching behavior and milk yield (Breuer et al., 2000).

In young animals, early interactions and fear of humans have been shown to have important effects later in life. Lürzel et al. (2015) reported that calves petted and stroked during the first $2 \mathrm{wk}$ of life showed less avoidance distance before disbudding and had greater average daily gain. Probst et al. (2012) found that calves that received gentle contacts in the first $3 \mathrm{wk}$ of life exhibited less movement backward in a stunning box during slaughter (at $10 \mathrm{mo}$ ), which was also associated with greater meat tenderness.

Many factors influence the quality of HAR (Waiblinger et al., 2003, 2006; Leruste et al., 2012; des Roches et al., 2016). Personality and attitude are believed to be the most important influencers of farmer behavior (Breuer et al., 2000; Waiblinger et al., 2002; Hanna et al., 2009). For instance, positive farmer attitudes toward dairy cattle were positively correlated with soft vocalizations and negatively correlated with negative tactile interactions (Breuer et al., 2000; Hemsworth et al., 2000). The quality of the HAR can also be influenced by factors that affect farmer attitudes, such as job satisfaction or experience (Hemsworth and Coleman, 2011). Demographic factors such as gender are shown to have an impact, with women presenting more positive behavior (Lensink et al., 2000).

Farm characteristics and management also affect the response of farm animals. Leruste et al. (2012) reported that larger herd size, less space allowance, and absence of environmental enrichment led to a higher proportion of fearful calves in an escape test. Individual animal characteristics also affect the HAR. These characteristics include health status (Cramer and Stanton, 2015) and temperament, which differs between breeds (Leruste et al., 2012; Grandin and Deesing, 2014). As described, HAR are multifactorial; therefore, identifying influential factors aids in the development of inter- vention strategies to improve the welfare of animals and the farmers who care for them.

In the current study, we aimed to investigate how different categories and combinations of variables (at the farm level, personnel level, and calf level) influence the HAR on farm. To quantify the HAR, we measured calf performance in an escape test.

\section{MATERIALS AND METHODS}

\section{Farm Selection}

Thirty dairy farms were visited during the springsummer season $2017(\mathrm{n}=17$ farms) and autumn-winter 2018 season ( $\mathrm{n}=13$ farms) in the region of Los Ríos, Chile. The selection criterion were artificial rearing of calves (separation from the dam before $7 \mathrm{~d}$ postpartum) and the use of group pens at some point in the preweaning period. All participant farms were convenience sampled by means of personal contacts in the industry and within the Universidad Austral de Chile. No exclusion criteria were placed upon herd size or dairy production type.

Because the participants could be sensitive to the objectives of the study and consequently change their behavior and responses, they were only partially informed of study objectives. They were told that the study aimed to evaluate the characteristics of the artificial breeding of dairy calves in the region. After the study was completed, all farms involved were given a report detailing the results. Farms were visited once.

Before data collection was initiated, 3 farms were visited to pilot-test the surveys and the measurements obtained from the calves and from the calf manager. The aims of the visits were to practice and standardize the escape test by the experimenter; to ascertain if calf managers were able to understand the statements in the surveys; and to check and practice the evaluation of the calf manager behavior. Any procedural modifications resulting from the pilot testing are specified in the subsequent sections where applicable. These farms were not included in the final data set.

The measurements were grouped as (1) calf escape test (the outcome of interest) and (2) explanatory variables (management and infrastructure; calf manager behavior, attitude, and background; and calf). To eliminate bias during the visit, measurements were carried out in the following order: calf manager behavior, calf manager attitudes and background, management and infrastructure measurements, escape test, and calf measurements. All tests were conducted by the same person on all farms to reduce the possible influence of different experimenters. 


\section{Calf Escape Test}

The escape test was always completed with an unfamiliar person during the herd visit. All farms had different schedules for moving calves from the individual hutches to group pens; consequently, only the unweaned calves in group pens were considered for evaluation. On average $23.3 \pm 7.3$ (SD) calves per farm were evaluated (a total of $n=698$ calves). The number of evaluated animals per farm depended on the total number of calves. If the farm had fewer than 30 calves, all were evaluated; if the farm had more than 30 calves, pens were chosen on a pseudo-random basis until 30 measurements were reached. On average $( \pm \mathrm{SD})$, calves spent $7.5 \pm 17.7 \mathrm{~d}$ in the individual hutches before being moved to group pens. The mean number of evaluated pens per farm was $2.9 \pm 1.7$ and an average of 9.2 \pm 6.9 calves were found per pen.

The test was carried out in the group pens and was performed only once per calf by the same experimenter (Caucasian female, brown hair, $1.58 \mathrm{~m}$ tall, wearing blue coveralls). The escape test was carried out according to Bokkers et al. (2009) by measuring the reaction of calves to the active approach of the experimenter. The escape test began when the experimenter entered the pen and waited $1 \mathrm{~min}$ for the calves to become accustomed to her presence. Next, she chose a calf and positioned herself at a distance of $1.5 \mathrm{~m}$ in front of the animal. If the calf turned its head in another direction to avoid her, the experimenter waited approximately $20 \mathrm{~s}$. If the calf did not direct its head toward her or showed a withdrawal response after this time, it was scored with 0 (see below). The test had 4 stages: (1) eye contact, (2) 1 step toward the calf with an extended arm, (3) a second step, and (4) an attempt to touch the calf's snout. The test ended when the calf moved, even if all 4 steps were not completed. Once the first stage began, and if the calf showed no withdrawal response, the experimenter waited $1 \mathrm{~s}$ to proceed to the next stage. The behavior of the calf was scored on a 5-point scale, with a score of 0 corresponding to an animal that avoided eye contact, a score of 1 for an animal that moved after the first step was taken, a score of 2 for an animal that stood still after the first step, a score of 3 for an animal that stood still after the second step, and a score of 4 for an animal that could be touched. All measurements were made in the morning after feeding, with the exception of 2 farms, where visits were scheduled between 1300 and $1500 \mathrm{~h}$, before the afternoon feeding.

\section{Explanatory Variables}

The information collected was grouped as management and infrastructure (application of structured survey and direct measurements); calf manager behavior, attitude, and background (application of structured surveys and observational measurements); and calf (direct measurements). The surveys were administered in Spanish; thus, all subsequent descriptions provided in the Materials and Methods represent English translations.

Management and Infrastructure. Information related to the management of the calves was collected by means of a face-to-face interview with the calf manager, the dairy farm manager, or both. The survey contained 6 questions (Table 1). Infrastructure measurements were carried out by the experimenter and included assessments of bedding material and space allowance.

Calf Manager Behavior, Attitude, and Background. All calves included in the escape test were weighed using the same electronic scale (SDS model IDS 701; Multibalanzas, Quillón, Región of Ñuble, Chile), which was transported to the farm by the experimenter. The behavior of the calf manager weighing the calves was assessed by the experimenter during the weighing procedure, which was done approximately 1 $\mathrm{h}$ before the escape test was performed. If more than 1 staff member was involved in weighing the calves, only the person in charge of the calves was observed. On 6 farms, the behavior of the calf manager could not be assessed due to the absence of this individual at the time of the visit or their engagement with other tasks. During the observation, which lasted approximately 30 min, the experimenter noted the number and nature of contacts between the calf manager and the calves as each calf was moved onto the scale, weighed, and then removed. Types of contacts observed between the

Table 1. Targeted area of management and scale used in the survey on calf management

\begin{tabular}{ll}
\hline Area of management & Scale \\
\hline Number of lactating cows present on the farm & Open-ended question \\
Number of calves present on the farm & Open-ended question \\
Are cows brought into a maternity pen to calve? & $\square$ Yes $\square$ No \\
At what stage postpartum do you separate the calf from the dam? & Open-ended question \\
How much time do the calves spend in the individual hutches? & Open-ended question \\
How many liters of milk do you feed the calves? & $\square \leq 4 \mathrm{~L} \square>4 \mathrm{~L}$ \\
\hline
\end{tabular}


Table 2. Positive, negative, and neutral interactions assessed between the calf manager and the calves

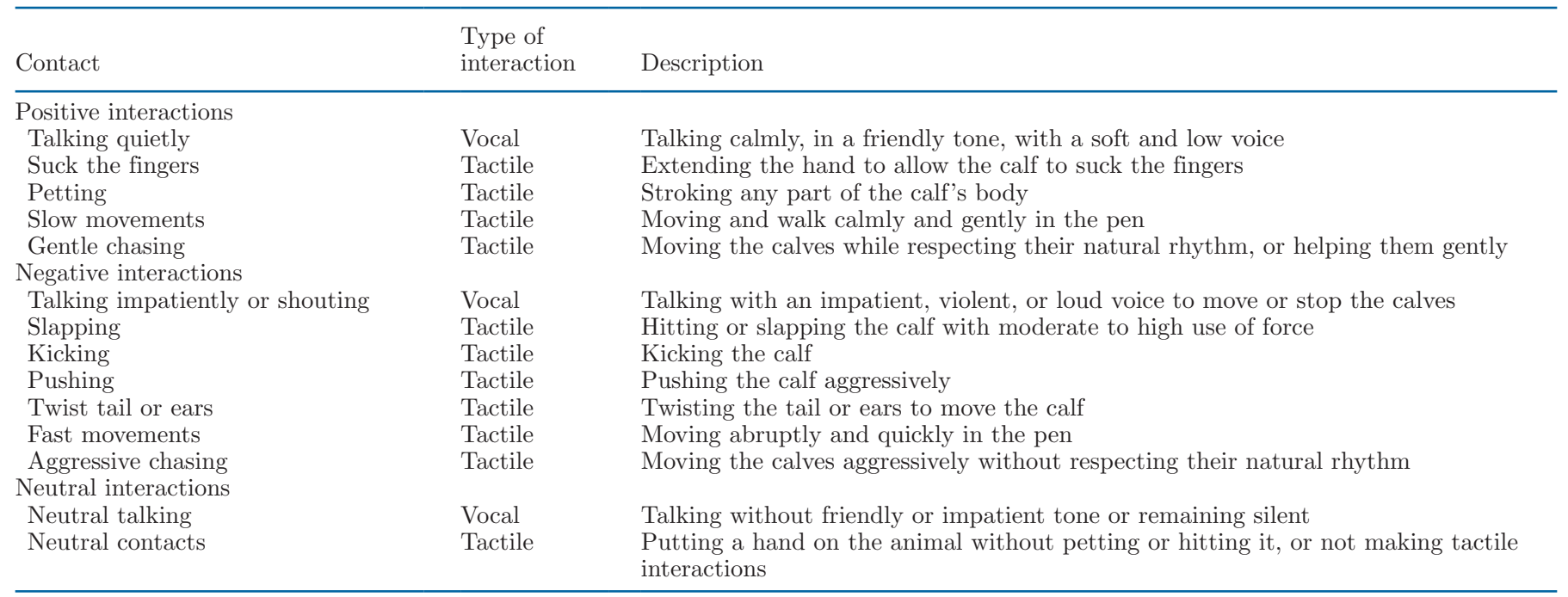

stockperson and the calf were adapted from Lensink et al. (2000) and Waiblinger et al. (2002) and are presented in Table 2. The interactions were classified as positive (talking quietly, allowing the calf to suck the fingers, petting, slow movements, gentle chasing), neutral (neutral talking, neutral contacts), or negative (talking impatiently or shouting, slapping, kicking, pushing, twisting the tail and ears, fast movements, aggressive chasing), and the proportion of positive and negative interactions was obtained in relation to the total. After the pilot farms were visited, the following contacts were added: gentle and aggressive chasing and twisting the tail and ears.

Calf manager attitudes were measured after all observations were completed. The calf managers were asked to fill out a questionnaire adapted from Lensink et al. (2000). The questionnaire was designed to infer the attitudes of the calf managers toward their calves and was divided into 3 sections (Table 3 ). Two calf managers were unable to complete the survey because they were nonliterate.

The second survey assessed the calf manager's background and contained questions related to gender, age, educational level, years of experience, training (any training related to animal welfare or animal handling), other jobs on the farm, number of calves, and one question about job satisfaction ("How much do you like working with the calves?"). The answer to the question was given on a 7 -point scale, where 1 represented "not at all" and 7 represented "a lot."

Calf. A health assessment for each calf was completed by a trained veterinarian and included evaluation for skin lesions, joint lesions, respiratory disease, ocular discharge, and diarrhea. All evaluations were

Table 3. Attitude survey of the calf managers

\begin{tabular}{|c|c|c|c|c|}
\hline Section & $\begin{array}{l}\text { Attitudes toward behaving } \\
\text { with calves inferred from: }\end{array}$ & $\begin{array}{l}\text { No. of } \\
\text { statements }\end{array}$ & Statements & 7-Point Likert scale \\
\hline 1 & $\begin{array}{l}\text { Managers' beliefs regarding the } \\
\text { sensitivity of calves to contact. }\end{array}$ & 5 & $\begin{array}{l}\text { Do you agree with the following } \\
\text { statements: Calves are sensitive to } \\
\mathrm{X} \text { (pain, petting, touching, talking, } \\
\text { kicking)? }\end{array}$ & $\begin{array}{l}1=\text { full disagreement to } \\
7=\text { full agreement }\end{array}$ \\
\hline 2 & $\begin{array}{l}\text { Managers' beliefs regarding the } \\
\text { importance of the calf manager } \\
\text { behavior for the success of the } \\
\text { farm. }\end{array}$ & 5 & $\begin{array}{l}\text { Do you agree with the following } \\
\text { statements: X (letting calves suck } \\
\text { your fingers, petting, being patient } \\
\text { with, working quietly with, talking to } \\
\text { calves) is important for the success of } \\
\text { the farm? }\end{array}$ & $\begin{array}{l}1=\text { full disagreement to } \\
7=\text { full agreement }\end{array}$ \\
\hline 3 & $\begin{array}{l}\text { Managers' own description } \\
\text { of their interactions with the } \\
\text { calves. }\end{array}$ & 5 & $\begin{array}{l}\text { How often do you X (pet your calves, } \\
\text { slap calves with your hands, let calves } \\
\text { suck your fingers, talk to your calves, } \\
\text { kick your calves)? }\end{array}$ & $\begin{array}{l}1=\text { never, } 4=\text { sometimes, } 7 \\
=\text { very often }\end{array}$ \\
\hline
\end{tabular}


based on the Welfare Quality protocol (Welfare Quality, 2009) and the protocol of the University of WisconsinMadison (https://www.vetmed.wisc.edu/dms/fapm/ fapmtools/8calf/calf_health_scoring_chart.pdf). The diseases and conditions considered were diarrhea, nasal discharge, cough, and lameness. If calves exhibited symptoms of any of these disease or conditions, they were classified as sick. Animals that did not stand up during the escape test (showing signs that their general health was compromised) were excluded. Additionally, age, sex, and breed of the calves were recorded.

The final list of variables collected consisted of 23 potential explanatory factors for calf performance in the escape test, divided into 3 categories: management and infrastructure, calf-manager factors, and calf-level factors (Table 4). A season variable was included in the management and infrastructure category.

All experimental procedures applied during the course of this study were discussed and approved for humans (Ord. 287) and animals (No. 359) by the institutional ethics committees of Universidad Austral de Chile.

\section{Statistical Analyses}

All data were analyzed using SAS (version 9.4, SAS Institute, Cary, NC). Descriptive statistics were obtained using PROC univariate. For data categorization, presence of maternity pen, calf manager training, and others jobs on the farm were coded as binary (yes/no). Amount of milk was categorized as $\leq 4 \mathrm{~L} / \mathrm{d}$ and $>4$ $\mathrm{L} / \mathrm{d}$. Space allowance was classified according to the legal minimum space for calves in the European Union as $\leq 1.8 \mathrm{~m}^{2} /$ calf and $>1.8 \mathrm{~m}^{2} /$ calf (as in Leruste et al., 2012). Bedding was divided into presence of bedding substrate (straw) and absence of bedding substrate. Calf manager sex and calf sex were classified as female or male. Job satisfaction, which was measured on a 7-point scale, was categorized as high (score 7) or low $(<7)$. This categorization was made based on the distribution of data, with $60 \%$ of calf managers scoring 7 (high) and 40\% scoring between 4 and 6 (low). Educational level was classified as low (incomplete primary education), medium (complete primary education and incomplete high school), and high (complete high school). Sickness was coded as healthy or sick (presence of at least one disease). Breed was classified as Holstein, Holstein crossbreed (Holstein + beef breed), or Jersey crossbreed.

Categorical Principal Components Analysis. Due to multicollinearity of individual questions pertaining to stockperson attitude, a principal components analysis (PCA) was conducted to reduce the 15 statements into a smaller set of linear combinations for use as potential predictors in the mixed logistic regression model. Because the attitude scores were obtained on an ordinal scale (from 1 to 7 ), an assumption of standard

Table 4. Potential explanatory variables to explain calf performance in an escape test ${ }^{1}$

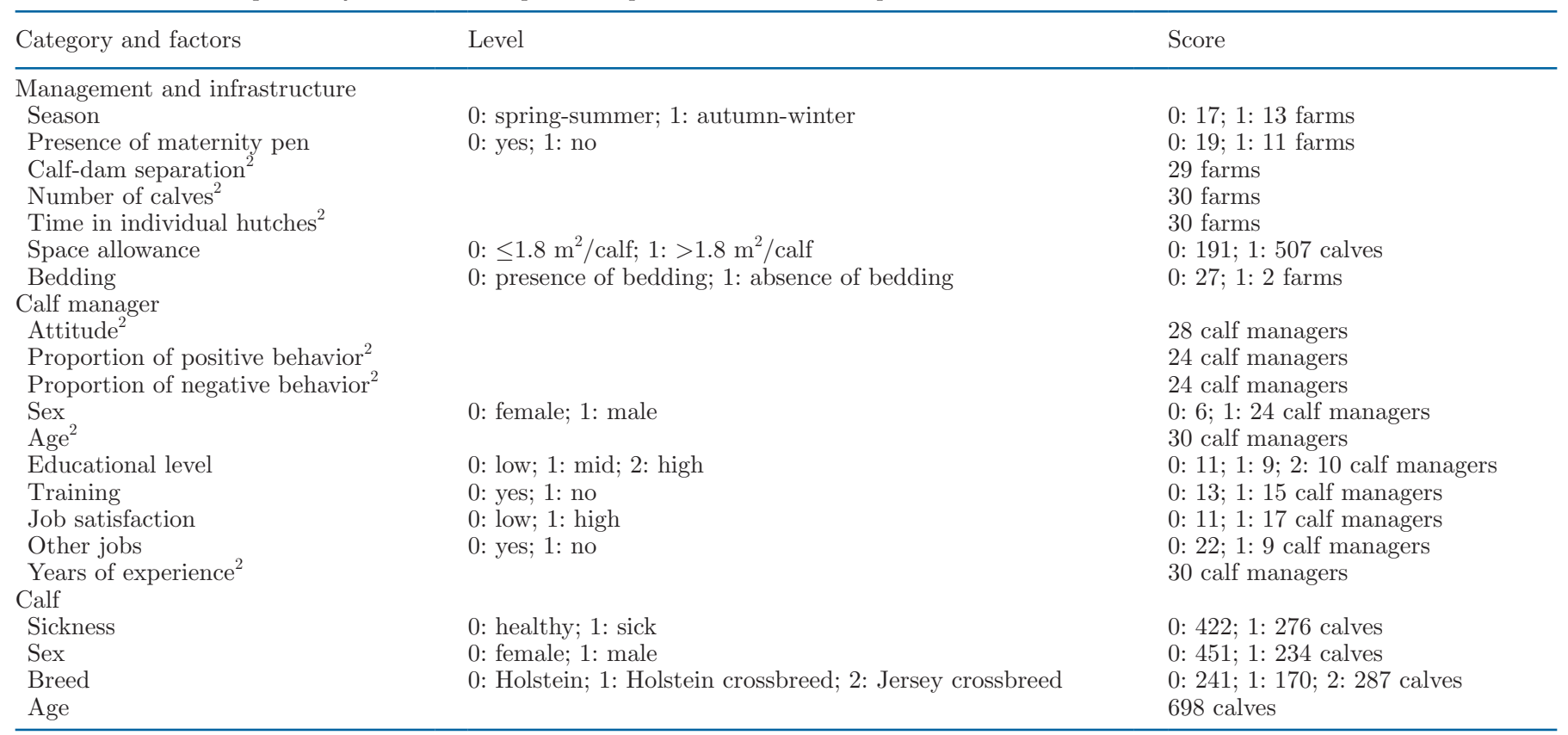

${ }^{1}$ The table was populated by means of the survey responses from 2 separate surveys (one pertaining to attitudes toward the calves and the other addressing demographic information and management practices) and direct observations of the calf handler and of the calves.

${ }^{2}$ Variables measured on a continuous scale. 
PCA (that variables must be measured on an interval or ratio scale) was violated; we therefore elected to conduct a categorical PCA (Linting and Van der Kooij, 2012). A monotonic spline transformation (of degree 2, with 2 internal knots) was applied to all ordinal variables using PROC Prinqual, and components were extracted using PROC Factor. Components were retained if their eigenvalue was $\geq 1$. A Varimax rotation was performed for ease of interpretation.

Mixed Ordinal Logistic Regression Modeling. Results from the escape test were grouped into 3 categories: friendly calf (score 4), cautious calf (score 1, 2, or 3 ), and fearful calf (score 0); this variable served as the outcome in all further analyses. First, univariable analyses (mixed ordinal logistic regression models using PROC Glimmix) were carried out for each factor separately, controlling for pen nested within farm as a random effect. The Satterthwaite approximation for the denominator degrees of freedom was applied, which accounts for the differences in degrees of freedom between farm-level and calf-level effects. Variables with results below the $P$-value threshold of $\leq 0.2$ were considered as potential predictors in the multivariable logistic regression model. These variables were assessed for multicollinearity using PROC corr. If a pair of variables was correlated at a threshold of $\mathrm{r} \geq|0.6|$, the variable most strongly related to the outcome in univariable analyses would be retained. A manual backward stepwise elimination procedure was used to obtain the final multivariable, mixed ordinal logistic regression model, with only variables significant at $P<0.05$ retained in the final model. Biologically relevant interactions were also considered for inclusion.

\section{RESULTS}

\section{Descriptive Statistics}

The mean number of lactating cows at the visited farms was $413.2 \pm 268.2(\mathrm{SD})(\min =50, \max =1,200)$. The mean number of calves per farm at the time of the visit was $148.6 \pm 135.9(\min =20, \max =585)$, with an average age of $46.4 \pm 23.6 \mathrm{~d}(\min =10 ; \max =144)$. Most of the calves evaluated were females (65.8\%). The distribution of main breeds on the farms was Holstein, $33.3 \%$; Holstein crossbreed, 26.7\%; and Jersey crossbreed, $40 \%$ (Table 4). Most of the farms $(77.4 \%)$ maintained a feeding regimen of $4 \mathrm{~L} / \mathrm{d}$ per calf, split into 2 feedings, while the remainder were offered between 5 and $8 \mathrm{~L}$. In terms of milk distribution method, $83.3 \%$ of the farms used milk bar feeders, while the rest used automated systems.

Seventy-seven percent of the calf managers were male and on average the calf manager's age was 43.9 $\pm 13.0(\min =25, \max =68)$. Among the calf managers, $38.7 \%$ reported low educational level (incomplete primary education); 29.0\%, median level (complete primary education and incomplete high school); and $32.3 \%$, high level (complete high school). Calf managers had $9.3 \pm 7.8(\min =1, \max =30)$ years of experience working with calves.

On 2 farms, no calves accepted being touched and only 1 farm had no calves scored as 0 (fearful). In total, $32.7 \%$ of the calves evaluated were classified as friendly, $30.8 \%$ as cautious, and $36.5 \%$ as fearful.

\section{Categorical PCA}

The 15 transformed statements from the attitude survey were reduced into 3 components based upon the eigenvalue criterion of $\geq 1.0$. These 3 components collectively accounted for $72.6 \%$ of the total variance. The first component (PC1) was labeled as "interacting with calves" and included statements such as "Petting calves is important for the success of the farm" and "How often do you kick your calves?" The second component (PC2) was labeled as "sensitivity" and included statements such as "Calves are sensitive to kicking" and "Calves are sensitive to touching." The last component (PC3) was labeled as "positive contact" and included statements such as: "How often do you let calves suck your fingers?" and "Letting calves suck your fingers is important for the success of the farm." Detailed results are presented in Table 5 .

\section{Risk Factor Analysis}

The univariable results are presented in Appendix Table A1. Of the 23 factors evaluated at the univariable stage, 17 were retained (at $P \leq 0.20$ ) for evaluation in the final multivariable model.

Complete results of the final model are presented in Table 6. Breed (Holstein, Holstein crossbreed, Jersey crossbreed), space allowance $\left(\leq 1.8 \mathrm{~m}^{2} /\right.$ calf, $>1.8 \mathrm{~m}^{2} /$ calf), other jobs on the farm (yes, no), training (yes, no), job satisfaction (high, low), attitude (positive contact [PC3]), and the proportion of calf managers' positive behavior were identified as influencing the behavior of the calves in the escape test $(P<0.05)$. In summary, the Holstein breed (compared with Holstein and Jersey crossbreeds) was predictive of a fearful response in the escape test. A space allowance higher than $1.8 \mathrm{~m}^{2} /$ calf was associated with a higher risk of observing fearful calves. Farms where the calf manager performed other jobs (besides working exclusively with the calves) was predictive of more fearful calf responses. Additionally, calf managers lacking training related to calf handling and welfare and those with low job satisfaction and 
Table 5. Varimax rotated pattern for transformed attitude scores ${ }^{1}$

\begin{tabular}{|c|c|c|c|}
\hline Results & $\begin{array}{l}\text { Component } 1 \text { : } \\
\text { Interacting with calves }\end{array}$ & $\begin{array}{l}\text { Component 2: } \\
\text { Sensitivity }\end{array}$ & $\begin{array}{l}\text { Component 3: } \\
\text { Positive contact }\end{array}$ \\
\hline Eigenvalue & 5.23 & 3.20 & 1.74 \\
\hline Percentage of total variance explained & 37.3 & 22.9 & 12.4 \\
\hline How often do you kick your calves? & -0.84 & 0.17 & 0.02 \\
\hline Petting calves is important for the success of the farm. & 0.83 & -0.25 & 0.00 \\
\hline How often do you pet your calves? & 0.79 & 0.09 & 0.39 \\
\hline Calves are sensitive to talking. & 0.66 & 0.57 & 0.36 \\
\hline How often do you slap your calves with your hands? & -0.60 & -0.18 & 0.16 \\
\hline Calves are sensitive to kicking. & 0.09 & 0.90 & -0.10 \\
\hline Calves are sensitive to touching. & -0.08 & 0.81 & 0.12 \\
\hline Working quietly with calves is important to the success of the farm. & 0.03 & 0.79 & -0.20 \\
\hline How often do you talk to your calves? & 0.46 & 0.68 & 0.25 \\
\hline Calves feel pain. & -0.10 & 0.55 & -0.38 \\
\hline
\end{tabular}

${ }^{1}$ For each retained principal component we provide the eigenvalue, the percentage of variance explained, and the contribution of each statement from the attitude survey. Results are ordered by contribution within component; contribution values within the component pattern are rounded to 2 decimal places.

a low proportion of positive contacts were predictive of more fearful calves. Finally, calf managers scoring higher in the attitude component positive contacts were associated with lower odds of fearful calves being observed.

\section{DISCUSSION}

Our study reaffirms the association between attitudes and the quality of the HAR (Des Roches et al., 2016).
The positive contact component of attitude of calf managers (PC3) was associated with friendlier calves in the escape test. The calf managers who prioritized positive contact in the attitude survey and self-reported that they performed these behaviors frequently had a greater proportion of calves touched by the experimenter. Lensink et al. (2000) described that calves that were stroked and allowed to suck the farmer's fingers exhibited fewer fear behaviors and interacted longer with the experimenter. This behavior appears to strengthen the

Table 6. Results ${ }^{1}$ of the mixed ordinal logistic regression model using farm-, calf manager-, and calf-level factors to predict calf response in an escape test

\begin{tabular}{|c|c|c|c|c|c|c|}
\hline Factor & Level & Estimate $^{2}$ & SE & $\mathrm{OR}^{3}$ & $\begin{array}{l}95 \% \text { Wald } \\
\text { CI for OR }\end{array}$ & $P$-value \\
\hline Intercept & & -0.69 & 0.68 & & & \\
\hline & $\begin{array}{l}\text { Jersey crossbreed } \\
\text { Holstein (referent) }\end{array}$ & 2.09 & 0.48 & 8.11 & $3.07,21.39$ & $<0.0001$ \\
\hline Space allowance & $\begin{array}{l}\leq 1.8 \mathrm{~m}^{2} / \text { calf } \\
>1.8 \mathrm{~m}^{2} / \text { calf (referent) }\end{array}$ & 0.86 & 0.41 & 2.37 & $1.03,5.45$ & 0.041 \\
\hline Training & $\begin{array}{l}\text { Yes } \\
\text { No (referent) }\end{array}$ & 1.18 & 0.45 & 3.26 & $1.31,8.08$ & 0.011 \\
\hline Satisfaction & $\begin{array}{l}\text { Low } \\
\text { High (referent) }\end{array}$ & -0.92 & 0.36 & 0.39 & $0.18,0.82$ & 0.014 \\
\hline Attitude: positive contact & & 0.54 & 0.18 & 1.73 & $1.19,2.51$ & 0.005 \\
\hline Proportion of positive interactions & & 0.02 & 0.006 & $1.11^{4}$ & $1.04,1.19$ & 0.001 \\
\hline
\end{tabular}

${ }^{1}$ Results are cumulated over the lower-ordered values (with 0 indicating fearful calves, 1 indicating cautious calves, and 2 indicating friendly calves).

${ }^{2}$ Estimates represent the slope $(\beta)$ estimates for the included fixed effects.

${ }^{3} \mathrm{OR}=$ odds ratio.

${ }^{4}$ Calculated based upon an increase of 5 units. 
human-animal bond and appears to be perceived as a positive interaction by the calves.

Underlying attitudes can predict the farmer's behavior toward cows and calves (Breuer et al., 2000; Lensink et al., 2000; Waiblinger et al., 2002), and a consistent correlation exists between the farmer's behavior and animal behavior (Breuer et al., 2000; Hemsworth and Coleman, 2011). Calves in our study were friendlier (more likely to be touched in the escape test) if the calf manager displayed a higher percentage of positive vocal and tactile interactions (petting, gentle chasing, talking quietly, letting the calves suck their fingers, slow movements) during calf weighing. This result adds to the large number of reports that associate the behavioral response of animals with the corresponding behavior of the farmer. More positive interactions and gentle handling are linked with animals showing fewer escape or withdrawal responses (Breuer et al., 2000; Hemsworth et al., 2000; Waiblinger et al., 2002, 2003)

We found that calf managers with a high score for the job satisfaction question ("How much do you like working with calves?") were associated with fewer fearful calves. Job satisfaction is a highly valuable aspect for dairy farmers (Bruijnis et al., 2013), which has the potential to influence animal welfare and performance (Hemsworth and Coleman, 2011). Also, job-related aspects could affect their behavior by modifying attitudes (Maller et al., 2005; Waiblinger et al., 2006). Maller et al. (2005) reported that farmers with more positive attitudes toward handling dairy cows (such as ease of movement) were correlated with enjoying the work during milking. Coleman et al. (1998) surveyed farmers in the pig industry and found that greater job satisfaction was correlated with lower negative attitudes toward working with pigs. They also found that negative attitudes were associated with negative behavior that was apparent during handling activities with breeding female pigs.

If the calf manager had other jobs on the farm aside from exclusively caring for the calves, animals avoided the experimenter more. This finding may be associated with the calf manager generally being expected to spend less time with the animals when preoccupied with other farm tasks. A calf manager who has other tasks on the farm may engage in a lower level of physical or visual contacts with the animals, affecting their behavioral response in the escape test. This effect has been described in other studies, but in the context of herd size. That is, a larger herd size has been associated with a decreased ability to touch cows in an avoidancedistance test and a higher proportion of calves scoring 0 in the escape test (Waiblinger and Menke, 1999; Leruste et al., 2012). With larger herds, farmers have less time to interact with their animals, so the frequency of contacts per animal is lower (Waiblinger and Menke, 1999). However, in the present study, no association was detected between the size of the herd and the results of the escape test.

In our study, we identified that calf managers with training (animal welfare or animal handling training) were associated with less-fearful calves. These results are consistent with a demonstrated effectiveness of training programs in animal production systems. For example, Hemsworth et al. (2002) reported that the application of a training program (cognitive-behavioral intervention) improved the attitudes and behavior of dairy farmers, and these improvements were in turn associated with shorter flight distances and better productive records in cows. Given that most of the calfcare personnel learn their job with the help of their experienced peers (Sischo et al., 2019), a link may exist between trained calf managers and increased knowledge and translatable skills. Additionally, Stup et al. (2006) stated that continuing training was associated with return on equity (a measure of financial performance) in dairy farmers. Training farmers is associated with the acquisition of new knowledge, but it is also linked to higher self-esteem and improvements in morale and job satisfaction (Stup et al., 2006; Hemsworth and Coleman, 2011). In Hemsworth and Coleman (2011), many of the factors that can influence farmer attitudes, behavior, and subsequent behavioral response of the animals are clearly interrelated. Coleman et al. (1998) reported a positive relationship between positive attitudes and the willingness of the farmers to attend training sessions and learn more about working in the industry. All these aspects have the potential to improve the quality of HAR and thus the productivity and welfare of the animals. This potential can be reflected in the behavioral response of the calves in the escape test.

In the current study, we identified that Holstein calves were more fearful than Holstein and Jersey crossbreeds. These results are consistent with those obtained by Leruste et al. (2012), who reported that dairy breeds compared with dual breeds or crossbreeds were more likely to score 0 in the calf escape test. Temperament and fear of humans have been shown to be heritable, and differences have been reported between breeds (Hemsworth et al., 1990; Grandin and Deesing, 2014). Lanier et al. (2000) reported that dairy breeds showed more sensitivity to sound and touch than beef breeds, perhaps explaining the increased fearfulness of Holsteins in our study compared with calves crossbred with beef breeds. In contrast, Murphey et al. (1981) reported that dairy breeds showed less avoidance than beef cows, concluding that this result was due to genetic selection and 
constant human handling in dairy production. In the current study, all visited farms implemented artificial rearing systems with daily human contact, suggesting a potential genetic component to our results.

The only farm-level factor associated with the behavioral response of the calves in the escape test was the space allowance. Larger space $\left(>1.8 \mathrm{~m}^{2} /\right.$ calf $)$ in the group pens was associated with more fearful calves. The escape test as administered in our study and similar variants of this test have been validated in previous research with both dairy cows and calves, and they have been determined to accurately reflect the HAR on farm (Lensink et al., 2000a, 2001). However, these studies did not evaluate whether space allowance affected calf response or whether the manifestation of the fear response may differ based upon the ability of the animal to withdraw from the fearful stimulus. It is difficult to interpret the increase in fearful calves in our study when higher space allowance per calf was provided. It is conceivable that immobility in the case of small space allowance was a reflection of fearfulness because fear responses such as passive avoidance or immobility have been previously noted in animals (Forkman et al., 2007; Hemsworth and Coleman, 2011). It is equally plausible that the smaller space allowance facilitated a great frequency of human-animal interactions, leading to decreased fear responses to humans. Given that a calf manager's daily chores include pen cleaning and calf feeding, it is certainly possible that calves are accustomed to the closest contact with their calf manager when housed in smaller spaces. The latter explanation better accords with the model results, given that positive interactions and attitudes were associated with a higher odds of being touched, even after adjusting for space allowance. In any case, our results pertaining to space allowance are discordant with previous findings (Leruste et al., 2012), and the influence of space on calf response in the escape test certainly warrants further exploration.

This study was limited by several factors. One of the limitations was the impossibility of making multiple visits to the farms to corroborate the measurements (Bokkers et al., 2009) and improve their reliability (Waiblinger et al., 2006). Additionally, we were not able to investigate if the order in which the test was performed affected the behavioral response of the animals. Another limitation was that the exact time between feeding and performance of the escape test was not known because the feeding schedule was not recorded. Even so, all measurements were made postprandial. Further studies may include exploring the motivations of animals toward humans during this type of test because misreading the animal's behavior can lead to erroneous interpretations that can be critical from a welfare point of view (e.g., the misclassification of hunger as friendliness). It is worth noting that caution toward humans (likely indicative of some low level of fear) is not necessary detrimental to the animal; however, extreme fear toward humans is likely to compromise welfare. To facilitate an accurate interpretation of an animal's reaction, knowing the extent to which social dynamics affect the individual response of the animal would also be useful.

To our knowledge, few studies (with the exception of Leruste et al., 2012) have included farm, farmer, and calf-level traits to evaluate the HAR by means of the escape test. Because these different trait levels may influence each other, a single multivariable model is a useful tool for evaluating the complexities of calf behavior and gaining a complete picture of motivating factors. Additionally, many studies addressing similar objectives have modeled dichotomous responses (percentage of touched animals or withdrawal responses) without exploring intermediate calf behaviors. In the present study, we employed an ordinal logistic regression model with 3 categories (fearful, cautious, friendly) to provide a more nuanced representation of calf responses in the escape test. Although other potential groupings may be hypothesized to be representative of calf behavior, we attempted to strike a balance between statistical parsimony and behavioral complexity through the use of 3 levels for the response variable. The odds ratios provided in the model (and their reciprocals) can allow for the comparison of friendly calves to their cautious and fearful counterparts, in addition to a comparison of fearful calves to their cautious and friendly counterparts. Moreover, many studies assessing attitudes treated Likert-type scales (e.g., responses scored as 1-7) as continuous variables, either as outcomes in linear regression models, as input variables in standard PCA, or as both. For categorical or ordinal variables, a suitable option is the categorical PCA (Linting and Van der Kooij, 2012).

In conclusion, we determined that factors at the farm, calf manager, and animal level affect the behavioral response of calves in an escape test. As in previous studies (Hemsworth et al., 2000; Hanna et al., 2009), our results showed the consistent relationship between characteristics of the farmer and animals' fear of humans. Identifying the intrinsic factors of farmers, which affect fear in animals, can potentially be used to select employees on a farm, based, for example, on their attitudes toward working with calves. Additionally, our results suggest that calf managers may benefit from training to improve their interactions with the animals they care for. These results support and highlight the 
importance of calf managers' attitudes and actions in influencing the behavior of calves in dairy production systems.

\section{ACKNOWLEDGMENTS}

We gratefully acknowledge the support of the Escuela de Graduados, Programa Magister en Ciencia Animal at Universidad Austral de Chile. General support for the University of British Columbia Animal Welfare Program is from the Canada's Natural Sciences and Engineering Research Council (NSERC) via the Industrial Research Chair Program with industry contributions from the Dairy Farmers of Canada (Ottawa, ON, Canada), British Columbia Dairy Association (Burnaby, BC, Canada), Westgen Endowment Fund (Milner, BC, Canada), Intervet Canada Corporation (Kirkland, QC, Canada), Zoetis (Kirkland, QC, Canada), Novus International Inc. (Oakville, ON, Canada), BC Cattle Industry Development Fund (Kamloops, BC, Canada), Alberta Milk (Edmonton, AB, Canada), Valacta (St. Anne-de-Bellevue, QC, Canada), and CanWest DHI (Guelph, ON, Canada). We thank Emerging Leaders in the Americas Program, offered by Global Affairs Canada and administered by the Canadian Bureau for International Education. We want to thank all the collaborators for their help in data collection and the valuable comments on the manuscript. We are particularly grateful to all farmers for their time and collaboration. The authors confirm that there are no known conflicts of interest associated with this publication and there has been no significant financial support for this work that could have influenced its outcome.

\section{REFERENCES}

Bokkers, E. A. M., H. Leruste, L. F. M. Heutinck, M. Wolthuis-Fillerup, J. T. N. van der Werf, J. Lensink, and C. G. van Reenen. 2009. Inter-observer and test-retest reliability of on-farm behavioural observations in veal calves. Anim. Welf. 18:381-390.

Breuer, K., P. H. Hemsworth, J. L. Barnett, L. R. Matthews, and G. J. Coleman. 2000. Behavioural response to humans and the productivity of commercial dairy cows. Appl. Anim. Behav. Sci. 66:273-288. https://doi.org/10.1016/s0168-1591(99)00097-0.

Breuer, K., P. H. Hemsworth, and G. J. Coleman. 2003. The effect of positive or negative handling on the behavioural and physiological responses of nonlactating heifers. Appl. Anim. Behav. Sci. 84:3-22. https://doi.org/10.1016/S0168-1591(03)00146-1.

Bruijnis, M., H. Hogeveen, C. Garforth, and E. Stassen. 2013. Dairy farmers' attitudes and intentions towards improving dairy cow foot health. Livest. Sci. 155:103-113. https://doi.org/10.1016/j.livsci .2013.04.005

Coleman, G. C., P. H. Hemsworth, and M. Hay. 1998. Predicting stockperson behaviour towards pigs from attitudinal and job-related variables and empathy. Appl. Anim. Behav. Sci. 58:63-75. https://doi.org/10.1016/S0168-1591(96)01168-9.

Cramer, M. C., and A. L. Stanton. 2015. Associations between health status and the probability of approaching a novel object or station- ary human in preweaned group-housed dairy calves. J. Dairy Sci. 98:7298-7308. https://doi.org/10.3168/jds.2015-9534.

des Roches, A. B., I. Veissier, X. Boivin, and E. Gilot-Fromont. 2016. A prospective exploration of farm, farmer, and animal characteristics in human-animal relationships: An epidemiological survey. J. Dairy Sci. 99:5573-5585. https://doi.org/10.3168/jds.2015-10633.

Forkman, B., A. Boissy, M.-C. Meunier-Salaün, E. Canali, and R. B. Jones. 2007. A critical review of fear tests used on cattle, pigs, sheep, poultry and horses. Physiol. Behav. 92:340-374. https://doi .org/10.1016/j.physbeh.2007.03.016.

Grandin, T., and M. Deesing. 2014. Genetics and the Behavior of Domestic Animals. 2nd ed. Academic Press, London, UK.

Hanna, D., I. A. Sneddon, and V. E. Beattie. 2009. The relationship between the stockperson's personality and attitudes and productivity of dairy cows. Animal 3:737-743. https://doi.org/10.1017/ S1751731109003991.

Hemsworth, P. H., G. J. Coleman, J. L. Barnett, S. Borg, and S. Dowling. 2002. The effects of cognitive behavioral intervention on the attitude and behavior of stockpersons and the behavior and productivity of commercial dairy cows. J. Anim. Sci. 80:68-78. https: //doi.org/10.2527/2002.80168x.

Hemsworth, P. H. 2003. Human-animal interactions in livestock production. Appl. Anim. Behav. Sci. 81:185-198. https://doi.org/10 .1016/S0168-1591(02)00280-0.

Hemsworth, P. H., J. L. Barnett, D. Treacy, and P. Madgwick. 1990. The heritability of the trait fear of humans and the association between this trait and subsequent reproductive performance of gilts. Appl. Anim. Behav. Sci. 25:85-95. https://doi.org/10.1016/ 0168-1591(90)90072-L.

Hemsworth, P. H., and G. J. Coleman. 2011. Human-Livestock Interactions: The Stockperson and the Productivity of Intensively Farmed Animals. 2nd ed. CAB International, Wallingford, UK.

Hemsworth, P. H., G. J. Coleman, J. L. Barnett, and S. Borg. 2000. Relationship between human-animal interactions and productivity of commercial dairy cows. J. Anim. Sci. 78:2821-2831. https://doi .org/10.2527/2000.78112821x.

Lanier, J. L., T. Grandin, R. D. Green, D. Avery, and K. McGee. 2000. The relationship between reaction to sudden intermittent movements and sounds and temperament. J. Anim. Sci. 78:1467-1474. https://doi.org/10.2527/2000.7861467x.

Lensink, B. J., A. Boissy, and I. Veissier. 2000. The relationship between farmers' attitude and behaviour towards calves, and productivity of veal units. Ann. Zootech. 49:313-327. https://doi.org/10 .1051/animres:2000122.

Lensink, B. J., X. Boivin, P. Pradel, P. Le Neindre, and I. Veissier. 2000a. Reducing veal calves' reactivity to people by providing additional human contact. J. Anim. Sci. 78:1213-1218. https://doi .org/10.2527/2000.7851213x.

Lensink, B. J., I. Veissier, and L. Florand. 2001. The farmers' influence on calves' behaviour, health and production of a veal unit. J. Anim. Sci. 72:105-116. https://doi.org/10.1017/S1357729800055600.

Leruste, H., E. A. M. Bokkers, L. E. M. Heutinck, M. WolthuisFillerup, J. T. N. van der Werf, M. Brscic, G. Cozzi, B. Engel, C. G. van Reenen, and B. J. Lensink. 2012. Evaluation of onfarm veal calves' responses to unfamiliar humans and potential influencing factors. Animal 6:2003-2010. https://doi.org/10.1017/ S1751731112001346.

Linting, M., and A. Van der Kooij. 2012. Nonlinear principal components analysis with CATPCA: A tutorial. J. Pers. Assess. 94:1225. https://doi.org/10.1080/00223891.2011.627965.

Lürzel, S., C. Münsch, I. Windschnurer, A. Futschik, R. Palme, and S. Waiblinger. 2015. The influence of gentle interactions on avoidance distance towards humans, weight gain and physiological parameters in group-housed dairy calves. Appl. Anim. Behav. Sci. 172:9-16. https://doi.org/10.1016/j.applanim.2015.09.004.

Maller, C. J., P. H. Hemsworth, K. T. Ng, E. J. Jongman, G. J. Coleman, and N. A. Arnold. 2005. The relationships between characteristics of milking sheds and the attitudes to dairy cows, working conditions, and quality of life of dairy farmers. Aust. J. Agric. Res. 56:363-372. https://doi.org/10.1071/AR04148. 
Munksgaard, L., A. M. De Passillé, J. Rushen, K. Thodberg, and M. B. Jensen. 1997. Discrimination of people by dairy cows based on handling. J. Dairy Sci. 80:1106-1112. https://doi.org/10.3168/jds .S0022-0302(97)76036-3.

Murphey, R. M., F. A. Moura Duarte, and M. C. Torres Penedo. 1981. Responses of cattle to humans in open spaces: Breed comparison and approach avoidance relationships. Behav. Genet. 11:37-48. https://doi.org/10.1007/BF01065826.

Probst, J. K., A. Spengler Neff, F. Leiber, M. Kreuzer, and E. Hillmann. 2012. Gentle touching in early life reduces avoidance distance and slaughter stress in beef cattle. Appl. Anim. Behav. Sci. 139:42-49. https://doi.org/10.1016/j.applanim.2012.03.002.

Sischo, W. M., A. Moore, R. Pereira, L. Warnick, D. L. Moore, J. Vanegas, S. Kurtz, K. Heaton, D. Kinder, J. Siler, and M. A. Davis. 2019. Calf care personnel on dairy farms and their educational opportunities. J. Dairy Sci. 102:3501-3511. https://doi.org/ 10.3168/jds.2018-15401.

Stup, R. E., J. Hyde, and L. A. Holden. 2006. Relationships between selected human resource management practices and dairy farm performance. J. Dairy Sci. 89:1116-1120. https://doi.org/10.3168/ jds.S0022-0302(06)72180-4.

Waiblinger, S., X. Boivin, V. Pedersen, M. V. Tosi, A. Janczak, E. Visser, and R. Jones. 2006. Assessing the human- animal relationship in farmed species: A critical review. Appl. Anim. Behav. Sci. 101:185-242. https://doi.org/10.1016/j.applanim.2006.02.001.
Waiblinger, S., and C. Menke. 1999. Influence of herd size on human-cow relationships. Anthrozoos 12:240-247. https://doi.org/ $10.2752 / 089279399787000156$.

Waiblinger, S., C. Menke, and G. J. Coleman. 2002. The relationship between attitudes, personal characteristics and behaviour of stockpeople and subsequent behaviour and production of dairy cows. Appl. Anim. Behav. Sci. 79:195-219. https://doi.org/10.1016/ S0168-1591(02)00155-7.

Waiblinger, S., C. Menke, and D. W. Fölsch. 2003. Influences on the avoidance and approach behaviour of dairy cows towards humans on 35 farms. Appl. Anim. Behav. Sci. 84:23-39. https://doi.org/10 .1016/S0168-1591(03)00148-5.

Welfare Quality. 2009. Welfare Quality ${ }^{\circledR}$ assessment protocol for cattle. Welfare Quality Consortium, Lelystad, Netherlands.

\section{ORCIDS}

J. Calderón-Amor 느 https://orcid.org/0000-0003-4183-2260

A. Beaver ๑ https://orcid.org/0000-0002-2953-9574

M. A. G. von Keyserlingk ๑ https://orcid.org/0000-0002-1427-3152

C. Gallo @ https://orcid.org/0000-0002-7257-3559 


\section{APPENDIX}

Table A1. Results ${ }^{1}$ of the univariable mixed ordinal logistic regression model using farm-, calf manager-, and calf-level factors to predict calf response in an escape test

\begin{tabular}{|c|c|c|c|c|c|c|}
\hline Factor & Level & Estimate $^{2}$ & $\mathrm{SE}$ & $\mathrm{OR}^{3}$ & $95 \%$ CI for OR & $P$-value \\
\hline Sex & $\begin{array}{l}\text { Female } \\
\text { Male (referent) }\end{array}$ & -0.44 & 0.22 & 0.64 & $0.41,0.98$ & 0.044 \\
\hline Calf age & & 0.002 & 0.004 & 1.00 & $0.99,1.01$ & 0.670 \\
\hline Breed & $\begin{array}{l}\text { Holstein } \\
\text { Holstein crossbreed } \\
\text { Jersey crossbreed (referent) }\end{array}$ & $\begin{array}{r}-0.06 \\
1.25\end{array}$ & $\begin{array}{l}0.43 \\
0.43\end{array}$ & $\begin{array}{l}0.94 \\
3.50\end{array}$ & $\begin{array}{l}0.39,2.24 \\
1.46,8.35\end{array}$ & 0.006 \\
\hline Calf-dam separation & & 0.55 & 0.22 & 1.01 & $1.00,1.02$ & 0.002 \\
\hline No. of calves in the calf barn & & 0.0004 & 0.001 & 1.00 & $0.99,1.00$ & 0.780 \\
\hline No. of calves in the pen & & 1.57 & 0.31 & 0.95 & $0.90,0.99$ & 0.03 \\
\hline Amount of milk & $\begin{array}{l}\leq 4 \mathrm{~L} \\
>4 \mathrm{~L}\end{array}$ & 0.81 & 0.46 & 2.26 & $0.90,5.68$ & 0.080 \\
\hline Days alone in hutches & & 0.02 & 0.01 & 1.02 & $0.99,1.05$ & 0.057 \\
\hline Proportion of negative interactions & & -0.01 & 0.006 & 0.98 & $0.96,0.99$ & 0.013 \\
\hline Sex & $\begin{array}{l}\text { Male } \\
\text { Female (referent) }\end{array}$ & -1.24 & 0.43 & 0.28 & $0.12,0.67$ & 0.005 \\
\hline Educational level & $\begin{array}{l}\text { Basic } \\
\text { Intermediate } \\
\text { High (referent) }\end{array}$ & $\begin{array}{l}0.39 \\
0.69\end{array}$ & $\begin{array}{l}0.43 \\
0.44\end{array}$ & $\begin{array}{l}1.48 \\
2.00\end{array}$ & $\begin{array}{l}0.61,3.58 \\
0.81,4.90\end{array}$ & 0.290 \\
\hline Training & $\begin{array}{l}\text { Yes } \\
\text { No (referent) }\end{array}$ & -0.93 & 0.37 & 0.39 & $0.18,0.82$ & 0.014 \\
\hline Job satisfaction & $\begin{array}{l}\text { Low } \\
\text { High (referent) }\end{array}$ & -0.60 & 0.40 & 0.55 & $0.24,1.23$ & 0.140 \\
\hline Other jobs on the farm & $\begin{array}{l}\text { Yes } \\
\text { No (referent) }\end{array}$ & -1.34 & 0.38 & 0.26 & $0.12,0.55$ & 0.001 \\
\hline Age & & 0.02 & 0.015 & 1.02 & $0.99,1.06$ & 0.069 \\
\hline Years of experience & & 0.04 & 0.02 & 1.04 & $0.99,1.10$ & 0.099 \\
\hline
\end{tabular}

${ }^{1}$ Results are cumulated over the lower-ordered values (with 0 indicating fearful calves, 1 indicating cautious calves, and 2 indicating friendly calves).

${ }^{2}$ Estimates represent the slope $(\beta)$ estimates for the included fixed effects.

${ }^{3} \mathrm{OR}=$ odds ratio. 